\title{
Technostress among Library Professionals: Possible Causes, Symptoms, Coping Strategies, and Future Proposals
}

\author{
Subhajit Panda*
}

\begin{abstract}
Technostress is the feeling of anxiety or mental pressure caused by working with multiple and rapidly changing computer systems, and mediating between these systems and the demands of the organisation, users, and personal life. This study investigated the nature and extent of technostress, the factors causing technostress, and the effect of it on professional and social lives among the library professionals in India. The study further explored the coping strategies to deal with technostress and gives a proposal for using the positive technology approach for technostress prevention and management. The study was carried through an online survey, with a structured questionnaire designed on a Google Forms. A total of 500 respondents were selected for the study over four designated domains, viz. library assistants, assistant librarians, deputy librarians, and librarians or university librarians. Ten preferred causes and coping strategies, and eight identified physiological and psychological symptoms they are subjected to for this study. The findings of the study may be used to develop strategies and policies which may facilitate librarians to avoid, adapt to, or mitigate technostress.
\end{abstract}

Keywords: Technostress, Technophobia, Techno-Insecurity, Techno-Overload, Techno-Invasion, Techno-Complexity, TechnoUncertainty, Library Professionals, Physiological Symptoms, Psychological Symptoms, Positive Technology, Coping Strategy

\section{Introduction}

With the increasing levels of library automation, both library staff and users often have to deal with concerns over how technology is going to impact them. During the last two decades, the advancement in ICT has not only changed the library environment drastically, but also altered work roles, expanded required skill sets, and increased uncertainty about future prospects of libraries and library services. Computer operating systems and software versions are changing so rapidly that by the time the library staff and users get used to one version of the software, the next version is released (Sami \& Pangannaiah, 2006). Library professionals are constantly eager to adapt to new technologies out of fear of becoming obsolete. At the same time, introduction of these new technologies can become a threat through its misuse, abuse, and overuse, resulting in technostress (Gaudioso et al., 2017). The term technostress is used synonymously with technophobia, computer phobia, computer anxiety, and computer stress; it is one of the negative effects of the continuous use of ICTs in libraries. It is the negative physiological and psychological link between people and the new technologies.

This article aims to present the main causes of technostress, its physiological and psychological problems, and coping strategies. Additionally, the study proposes how positive technologies (Riva et al., 2012) can help prevent technostress, and promote positive work experiences and general well-being through an effective organisational safety culture (Galimberti, 2014; Galimberti et al., 2016).

\section{Study Background}

\section{Definition}

Brod (1984), a pioneer in this particular field, had coined and defined the term technostress as "A modern disease

* Assistant Librarian, University Library, Chandigarh University, Punjab, India. Email: subhajit.e9641@cumail.in; Orcid id: http://orcid.org/0000-0002-1578-1159 
of adaptation caused due to lack of an individual's ability to cope with new computer technologies in a healthy manner. It manifests itself in two distinct but related ways: in the struggle to accept computer technology and in the more specialised form of over-identification with computer technology" (p.16).

David-Mallis (1998) identified technostress as a condition whereby a person has to adapt to new technology, especially when there is a shortage of equipment, support, or the technology itself.

Weil and Rosen (1997) defined technostress as any negative impact on attitudes, thoughts, behaviours, or body physiology that is caused either directly or indirectly by technology.

According to Clark and Kalin (1996), the real definition of technostress is "resistance to change". They claimed that technology is not the culprit, because computer and technologies are just tools and stress is a natural reaction. Thus, they suggested that in order to manage technostress, it is the change that has to be managed and not the technology.

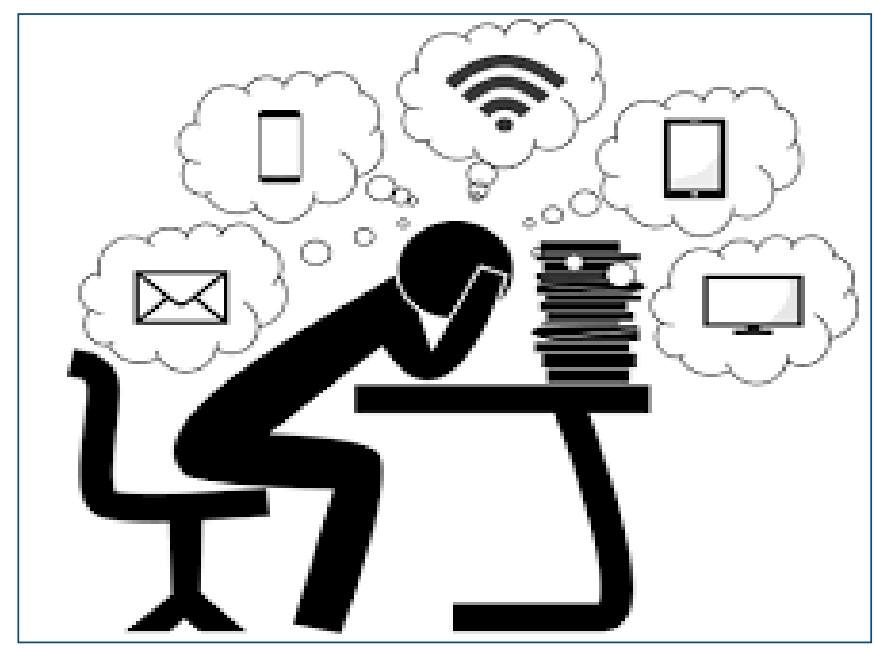

Fig. 1: Technostress: The Dark Side of the usage of Technology

\section{Factors Inducing Technostress}

There are generally two main groups of factors inducing technostress (Owusu-Ansah et al., 2016):

- Environmental Factors: These factors refer to poor working conditions, insufficient lighting, inadequate equipment, inadequate security measures, user incompatibility, noisy equipment, software limitations, lack of funding, electrical issues, risk of accidental data loss, and insufficient knowledge and staff, which may cause people to suffer technologyrelated stress.

- Social Factors: These factors refer to conflict of interest caused by the use of technology, power struggles, work and role changes, anxiety over loss of employment, work fragmentation, and hierarchal changes that may cause people to suffer technologyrelated stress.

\section{Components of Technostress}

- Techno-Overload: A situation where the ICT users are compelled to work more and work faster.

- Techno-Invasion: A situation where ICT users feel that they can be contacted anytime or anywhere, thereby losing their privacy and downtime, causing an unclear boundary between work-related and personal contexts.

- Techno-Complexity: A situation where ICT users feel that their skills are insufficient, because of the complexity of ICTs, which then compels them to spend all their time and effort in learning and understanding the use of new applications and updating their skills.

- Techno-Insecurity: A situation where the ICT users feel insecure in their jobs, either worried about being replaced by the new ICTs or by other people who have a better understanding of the new gadgets and computing devices.

- Techno-Uncertainty: A condition where the ICT users feel uncertain and mentally disturbed since ICTs are endlessly shifting and need upgrading.

These stressors may have impact both at the private and organisational levels, endangering the work-life balance (Brivio et al., 2018).

\section{Technostress in Libraries}

Library professionals in academic libraries have to work in an ever changing technological environment. They cannot remain idle as they have to cater to the learning 
needs of the library users. They have to work with multiple and rapidly changing computer systems, upgrade the computer hardware and software, manage electronic resources, meet the information demands of their parent institution, students, faculties, and other staff, and maintain a balance between their personal life and work life. As noted by Al-Qallaf (2006), "today, librarians provide access to eclectic e-collections, create and maintain digital content, support e-learning, provide real time e-reference, negotiate contracts and licensing agreements, and struggle with the economics of electronic information" (p.168). Therefore, the usage of advanced ICTs like integrated computer systems, multiple databases, CD-ROMs, the Internet, and the World Wide Web (WWW) has given rise to an enormous amount of strain on library professionals, resulting in technostress.

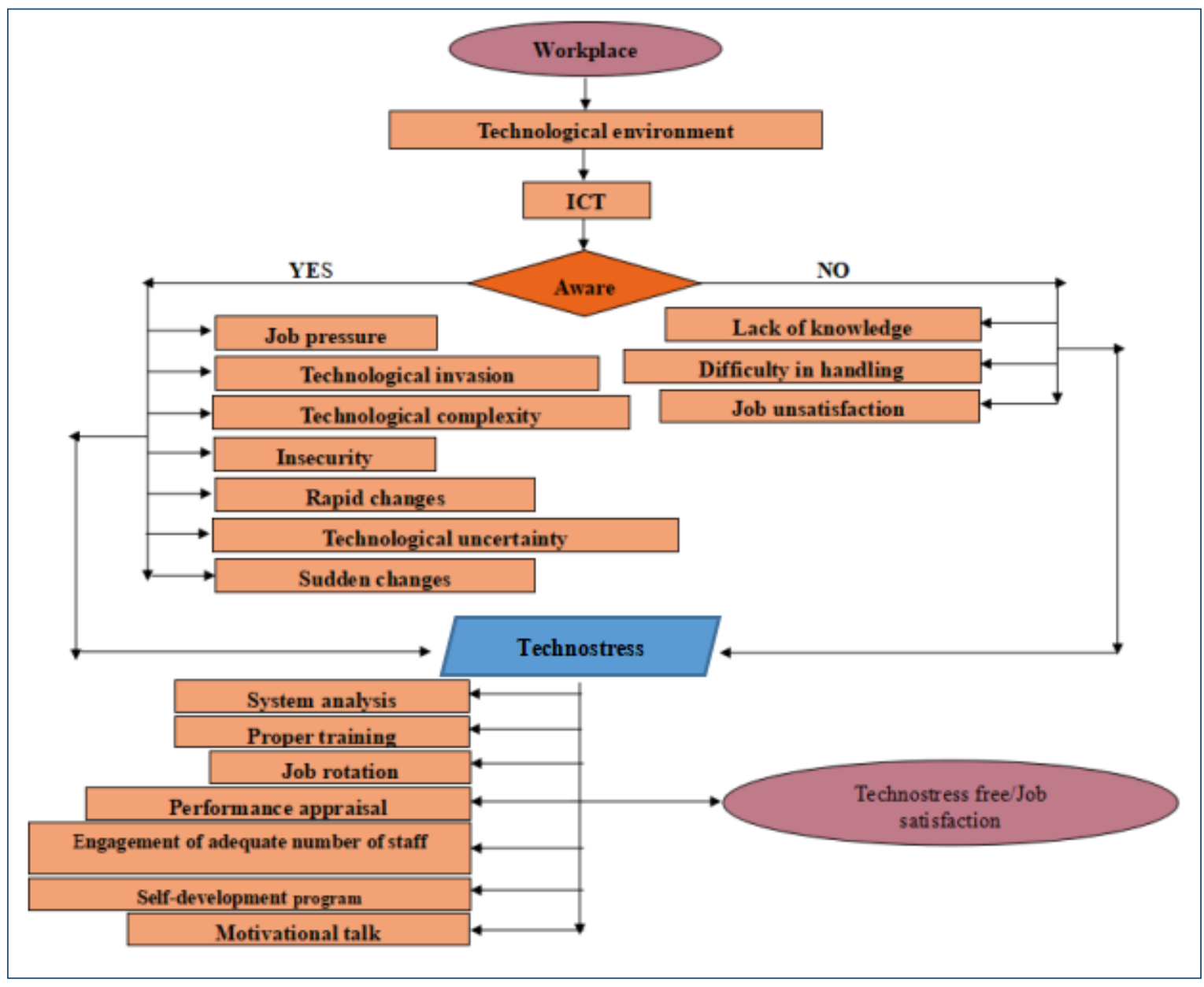

Fig. 2: Flowchart of Technostress Management in Libraries

\section{Review of the Literature}

Research on technostress has been conducted in different domains, such as in medicine (Arnetz \& Wiholm 1997), psychology (Brod, 1984; Weil \& Rosen, 1997), and from economical and organisational perspectives (Brillhart, 2004; Tarafdar et al., 2005; Wang et al., 2008). Some significant researches are discussed in this section, to give a preliminary idea about the present study, its need and significance, and how it adds some more to the existing literature.

The purpose of the paper by Sami and Pangannaiah (2006) was to review the impact of information technologies on users of libraries with reference to the concept of 'technostress', the inability to cope with the new computer technologies healthily or positively. A distributed cognition perspective of human-technology 
interaction was investigated by Yuvaraj and Singh (2015) through LimeSurvey, to explore technostress, its effects, and coping strategies to prevent it among university librarians in Delhi. A similar study was found in the paper by Ogada, Kwanya, and Kiplang'at (2019), where they investigated the nature and extent of technostress among technical university librarians in Kenya. Ahmad and Amin (2012) defined in their paper the degree of technostress caused by the highly automated workplace environment among academic librarians in Malaysian public universities. Aghwotu and Owajeme (2010) sought to examine the causes, symptoms, and coping strategies of technostress among university librarians ( sample size $=5$ ) in Edo and Delta State, Nigeria. Jena and Mahanti (2014) analysed the factors causing technostress among Indian academicians $(\mathrm{N}=116)$ by conducting a survey using an online questionnaire. Owolabi, Aregbesola and Oyesola (2015) focused their study on identifying causes of technostress among library staff at Landmark University, Omu-Aran, and proffering solutions. Hsiao (2017) studied the compulsive usage of mobile applications and their negative effect on people's health and social interaction. Khasawneh (2018) examined the literature to highlight the hairline gap between computer anxiety/phobia and technophobia.

\section{Scope of the Present Study}

The study surveys factors that cause technostress in workplaces, which results in physiological and psychological problems for the library professionals, and tries to find possible coping strategies to get rid of technostress. In today's critical situation, the outbreak of COVID-19, the use of digital technology and digital media as a means of providing information has increase. Library professionals now work remotely through an online help desk, and 'Ask a Librarian' as a virtual reference provider. As a result, the techno working time of all library professionals has increased significantly, thus gradually increasing the effect of technostress.

\section{Objectives of the Study}

- To find out possible reasons for technostress among library professionals.
- To identify the physiological problems resulting from technostress among library professionals.

- To identify the psychological problems resulting from technostress among library professionals.

- To find out possible coping strategies or solutions to get rid of technostress.

\section{Research Methodology}

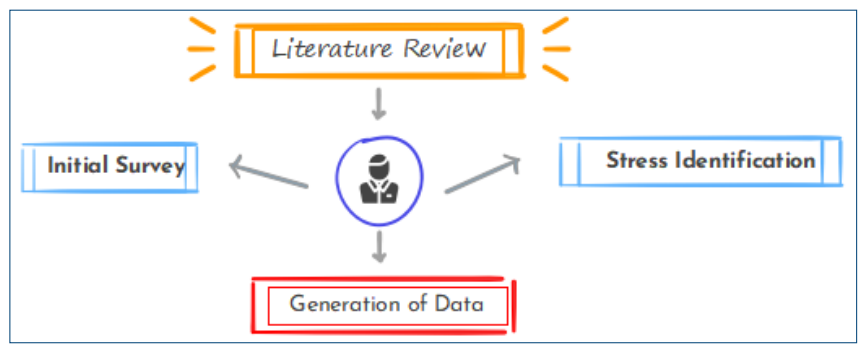

Fig. 3: Research Design

The research framework for this survey was designed upon a structured research questionnaire created through Google Forms and circulated online among different social platforms (e.g. Facebook, WhatsApp, Telegram, LinkedIn, Academia, and so on), and also via email to the eminent LIS professionals. The questionnaire contained some specific causes of technostress, identified physiological and psychological symptoms resulting from technostress, and possible solutions. It took almost two months (August 2020 to October 2020); around 749 participants from different parts of India took part in this survey. The target group for this study was the library professionals, which was further categorised into four groups according to their designations, viz. library assistants, assistant librarians, deputy librarians, and librarians. From the collected 749 respondents, 123 were not affected by technostress in their working place. The research sample was selected from the remaining 626 people, after proper analysis of the responses, which were adequate, authentic, and complete. The final selected sample universe $(\mathrm{N})$ for the study was 500 library professionals, including 365 library assistants (LA) (73\%), 100 assistant librarians (AL) (20\%), 15 deputy librarians (DL) (3\%), and 20 librarians or university librarians (UL) (4\%); among them, 279 (56\%) were women, 184 (37\%) men, and 37 (7\%) chose to not reveal their gender. 


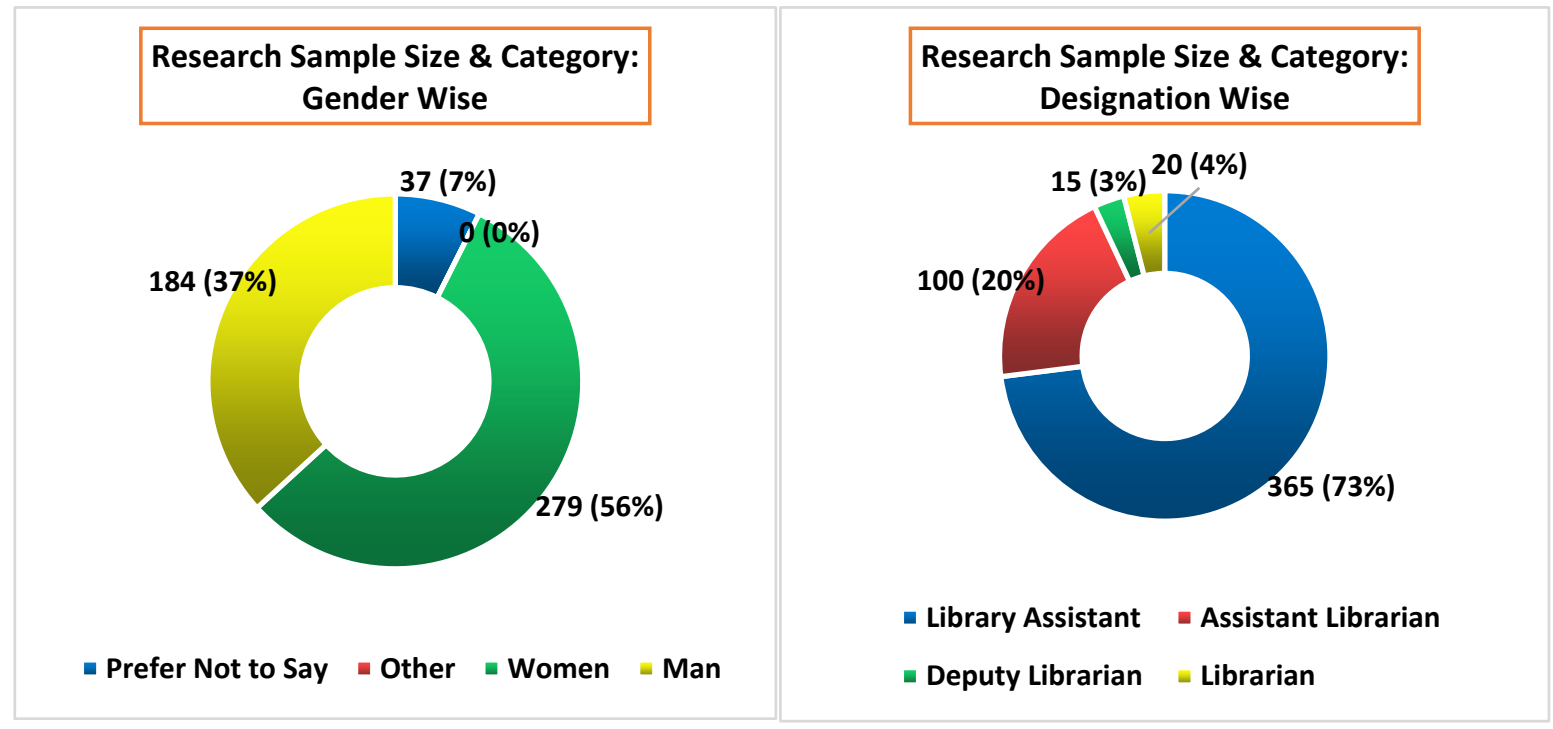

Fig. 4: Research Sample Size and Category (Gender- and Designation-Wise)

\section{Results and Discussions}

\section{Techno-Working Hours}

The time an employee uses IT in the workplace is the measure of his techno-working hours. As our study focused particularly on technostress, this factor considers the techno-working hours of the LIS professionals, rather than only their working hours. The study questionnaire provides three options for the respondents, viz. 0-4 (minimum techno-working time), 4-8 (moderate technoworking time), and $>8$ (greater than usual office hours).

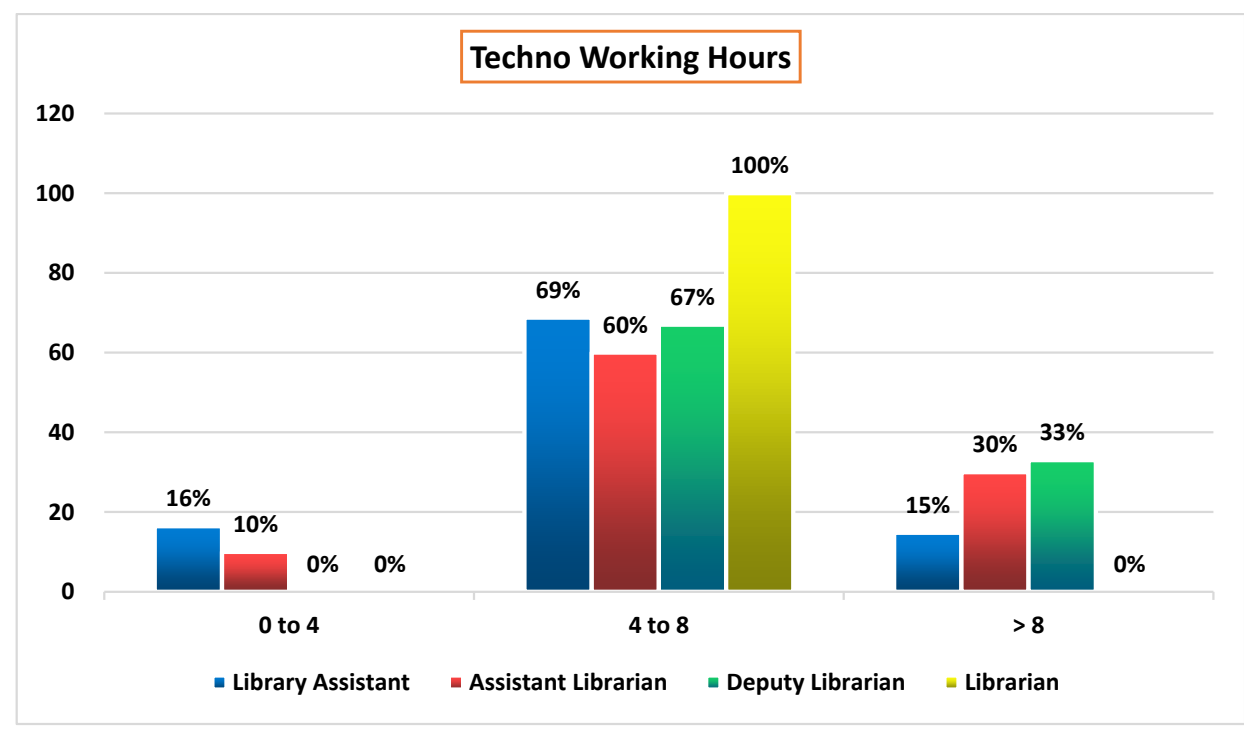

Fig. 5: Techno-Working Hours (Designation-Wise)

From Fig. 5, it can be shown that a maximum number of LIS professionals use IT in their workplace between four to eight hours: $69 \%$ (251) library assistants, $60 \%$ (60) assistant librarians, 67\% (12) deputy librarians, and 100\% (20) librarians. Additionally, some of the library assistants and assistant librarians chose zero to four hours as their techno-working time (16\% LA and 10\% AL), whereas other library assistants, assistant librarians, and deputy librarians work more than eight hours (15\% LA, 30\% AL, and $33 \%$ DL) with IT. 


\section{Perceived Stress}

In this study, the amount of stress is measured by a threepoint scale, viz. low, moderate, and high. Here, low stress indicates irritation, headache, finger and back pain, and so on, while medium and high stress deals with serious issues, viz. blurred vision, high blood pressure, heart problems, depression, and so on.

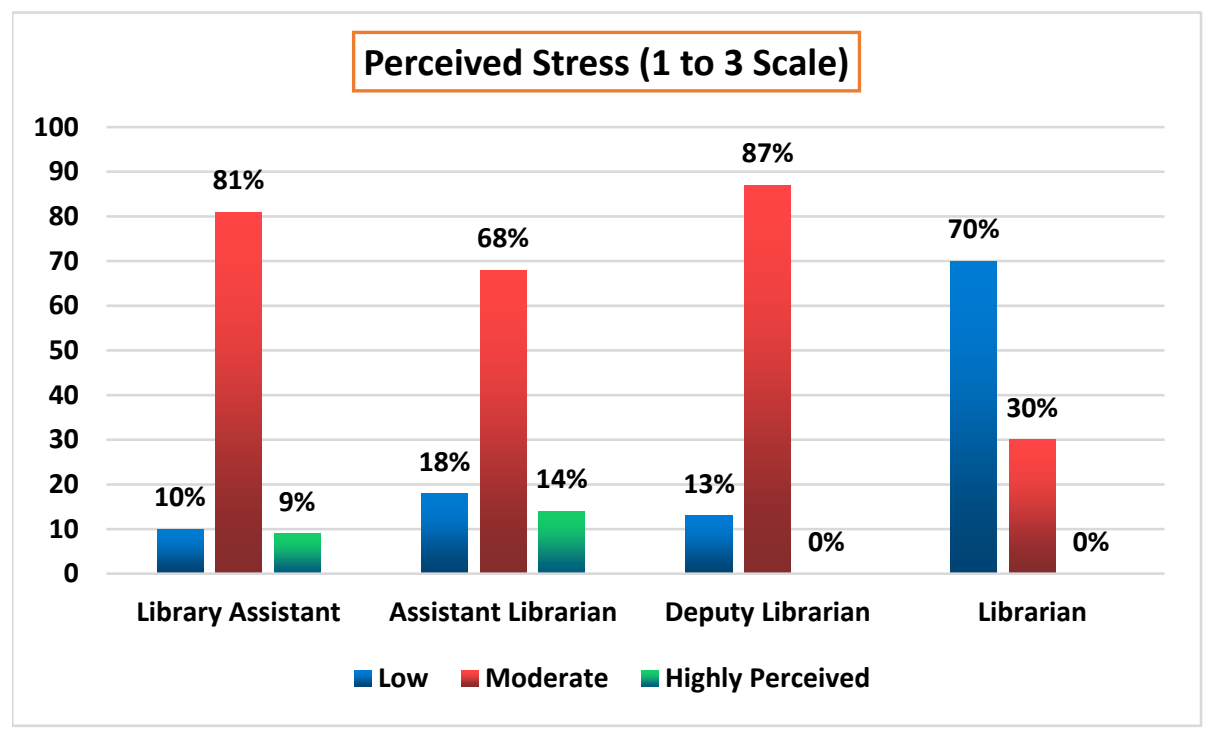

Fig. 6: Perceived Stress (Three-Point Scale)

Fig. 6 indicates that among the four types of designations, a majority of the first three types, i.e. LA (81\%), AL (68\%), and DL (87\%) perceive moderate stress levels, although $70 \%$ of university librarians chose low stress levels. Again, only $9 \%$ of LA and 14\% of AL perceived high stress levels.

\section{Techno-Working Hours vs. Perceived Stress}

Techno-working hour is the work time of a LIS professional spent sitting in front of computers, or working with IT; these are the primary reasons for suffering from technostress. Thus, the current study tries to find any relation between techno-working hour and perceived stress, without taking the working hour as a study variable.

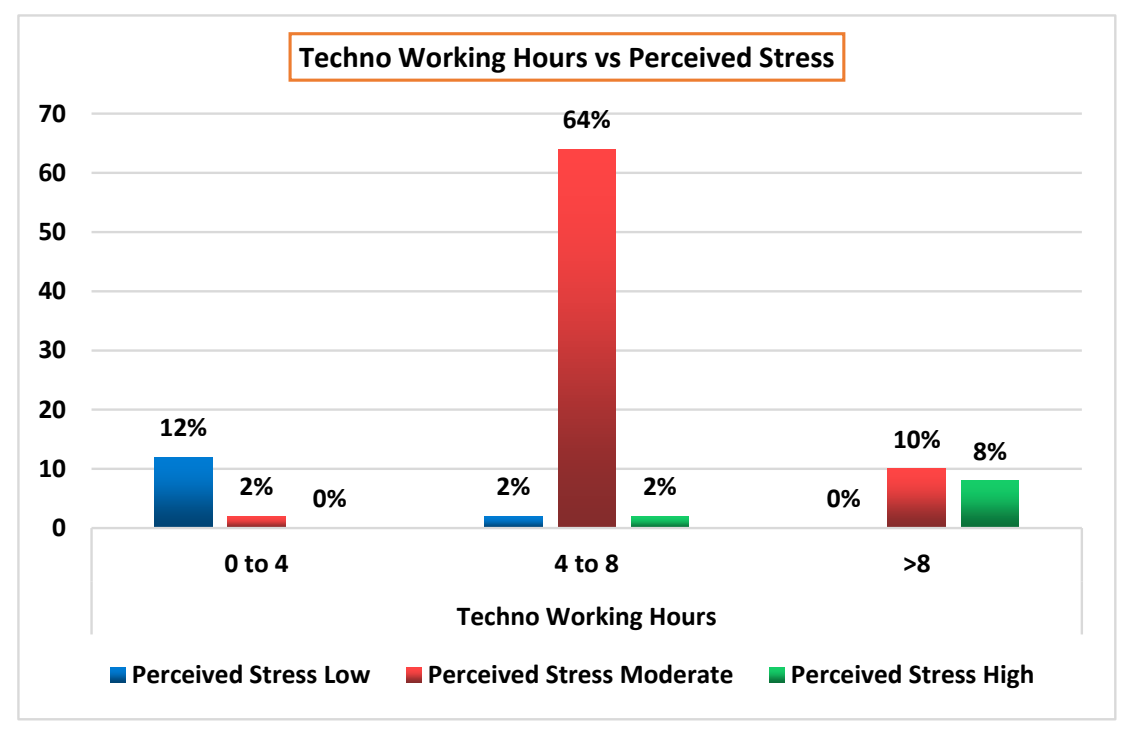

Fig. 7: Techno-Working Hours vs. Perceived Stress 
From Fig. 7, it can be identified that with increasing techno-working time (from 0-4 to 4-8), the perceived stress increases significantly. Out of a total of $14 \%$ of lowstress LIS professionals, $12 \%$ have $0-4$ hours of technoworking time, whereas, out of the $68 \%$ of moderately stressed LIS professionals, $64 \%$ have $4-8$ techno-working hours. However, in the case of LIS professionals with $>8$ techno-working hours, out of a total of $18 \%$ respondents, $10 \%$ suffer from moderately perceived technostress and $8 \%$ suffer from highly perceived technostress.

\section{Causes of Technostress among Library Professionals}

There are several reasons for the impact of technostress among LIS professionals. It varies depending on the workplace, work culture, work instrument, job responsibility, job timing, personal immunity, personal behaviour, old disease, and several other factors. The following are ten such causes, included in the research questionnaire as a multi-response question for the online survey:

- Information overload

- Pace of technological change

- Increased workload

- Lack of proper training

- Networking problems and security issues

- Lack of standardisation of hardware and software

- Prolonged sitting in front of computers

- Ergonomic hazards

- Vendor-produced databases

- Change in work role

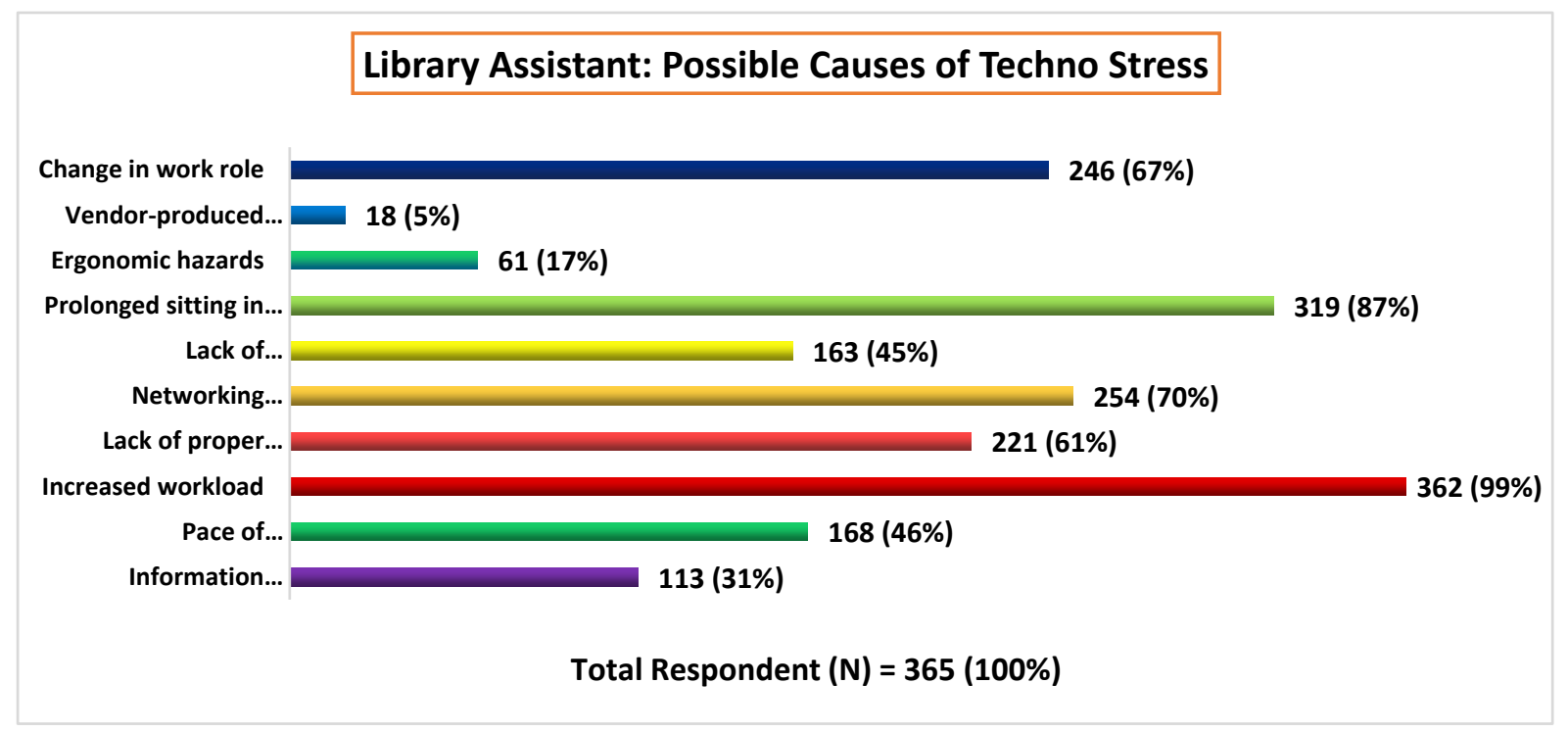

Fig. 8: Possible Causes of Technostress (Library Assistants)

Fig. 8 shows that a majority of the library assistants (99\% or 352) chose increased workload, prolonged sitting in front of computers $(87 \%$ or 319$)$, and networking problems and security issues $(70 \%$ or 254$)$ as the top three causes of their technostress, while vendor-produced databases was the least chosen one $(5 \%$ or 18).

Out of the 100 assistant librarian respondents, a majority chose prolonged sitting in front of computers (100 or
$100 \%$ ), information overload (91 or 91\%), and ergonomic hazards $(88$ or $88 \%$ ) as the cause of their technostress, whereas change in work role ( 2 or $2 \%$ ) and lack of proper training ( 23 or $23 \%$ ) were the least chosen.

In the case of deputy librarians, all the 15 (100\%) respondents chose prolonged sitting in front of computers and information overload as the cause of their technostress, while none of them $(0 \%)$ chose change in work role or lack of proper training (see Fig. 10). 


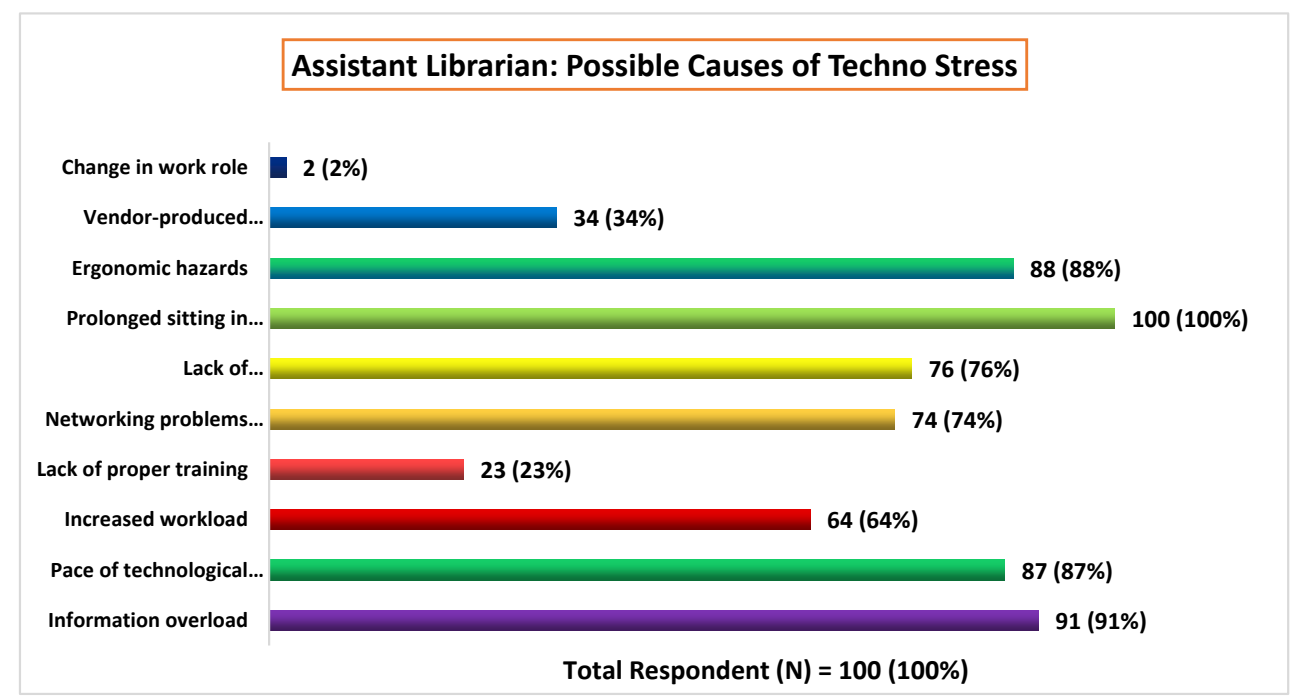

Fig. 9: Possible Causes of Technostress (Assistant Librarians)

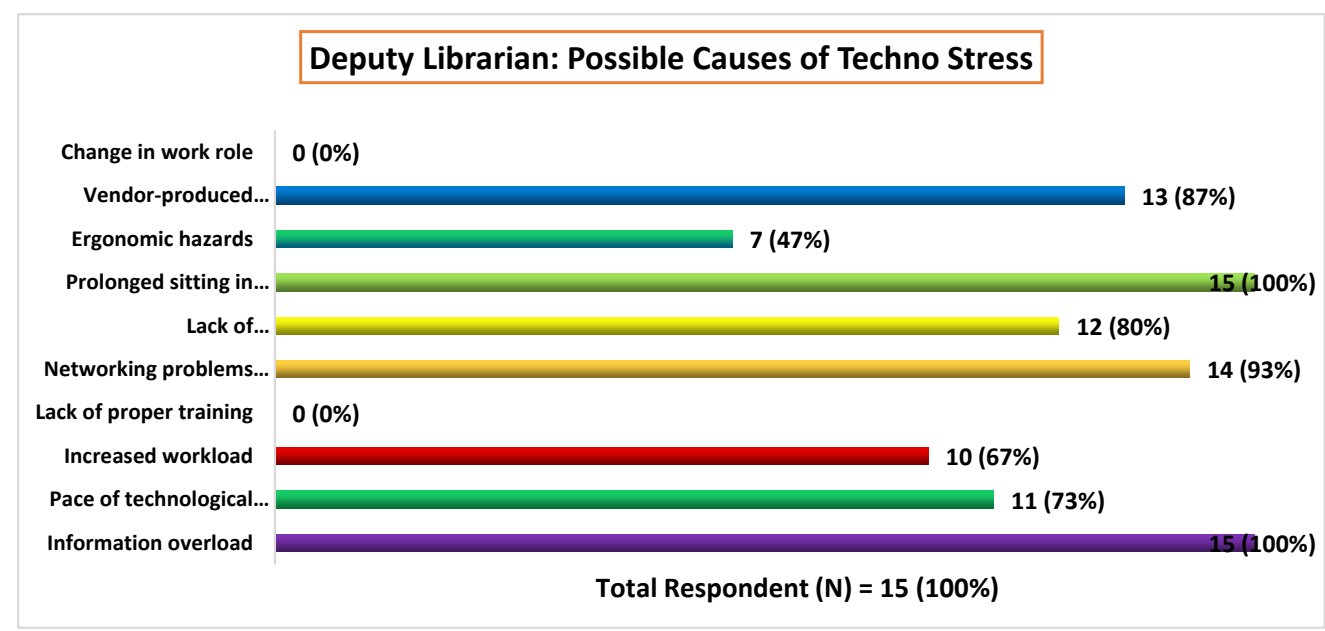

Fig. 10: Possible Causes of Technostress (Deputy Librarians)

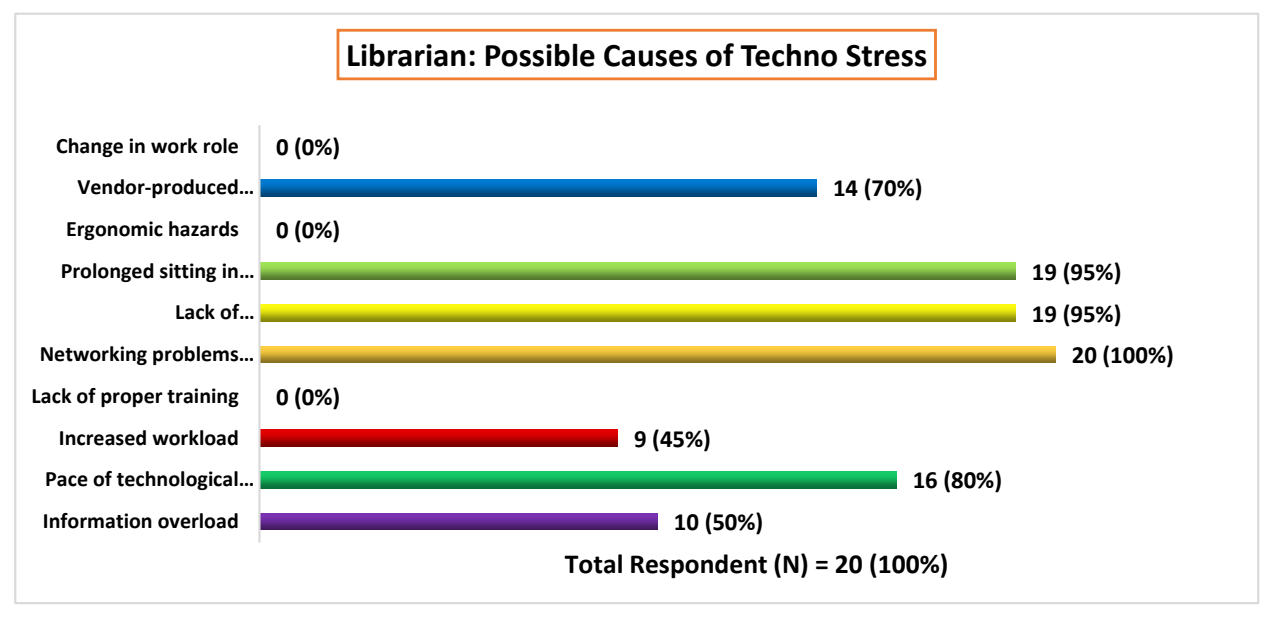

Fig. 11: Possible Causes of Technostress (Librarians or University Librarians) 
Among the 20 UL respondents, the top selected causes of technostress are networking problems and security issues (20 or $100 \%$ ), followed by prolonged sitting in front of xomputers (19 or $95 \%$ ) and lack of standardisation of hardware and software (19 or 95\%). The respondents did not choose causes like change in work role, ergonomic hazards, and lack of proper training.

\section{Physiological and Psychological Symptoms of Technostress among Library Professionals}

Research shows that factors that contribute to technostress (Ragu-Nathan et al., 2008), include techno-invasion, techno-overload, techno-complexity, techno-insecurity, and techno-uncertainty. The specific causes for these factors include change in work role, vendor-produced databases, prolonged sitting in front of computers, networking problems and security issues, increased workload, information overload, and so on. Additional causes include lack of support during testing, implementation, and use of the ICTs adopted by the library; discomfort and fatigue resulting from multitasking, as ICTs allow for completion of more tasks in a lesser amount of time (Ragu-Nathan et al., 2008); frequent interruption of assigned tasks due to the ongoing stream of communication (Mark et al., 2008). These stressors, together with a lack of personal coping mechanisms, create technostress in the work environment, causing both physiological and psychological consequences (Brivio et al., 2018).

\section{Physiological Symptoms}

Out of several physiological symptoms, in this study, the following eight particular symptoms were selected for inclusion in the questionnaire.

- Blurred vision

- Joint pain

- Back pain

- Headaches

- Hand and wrist pain

- Rapid heart rate

- Insomnia

- High blood pressure

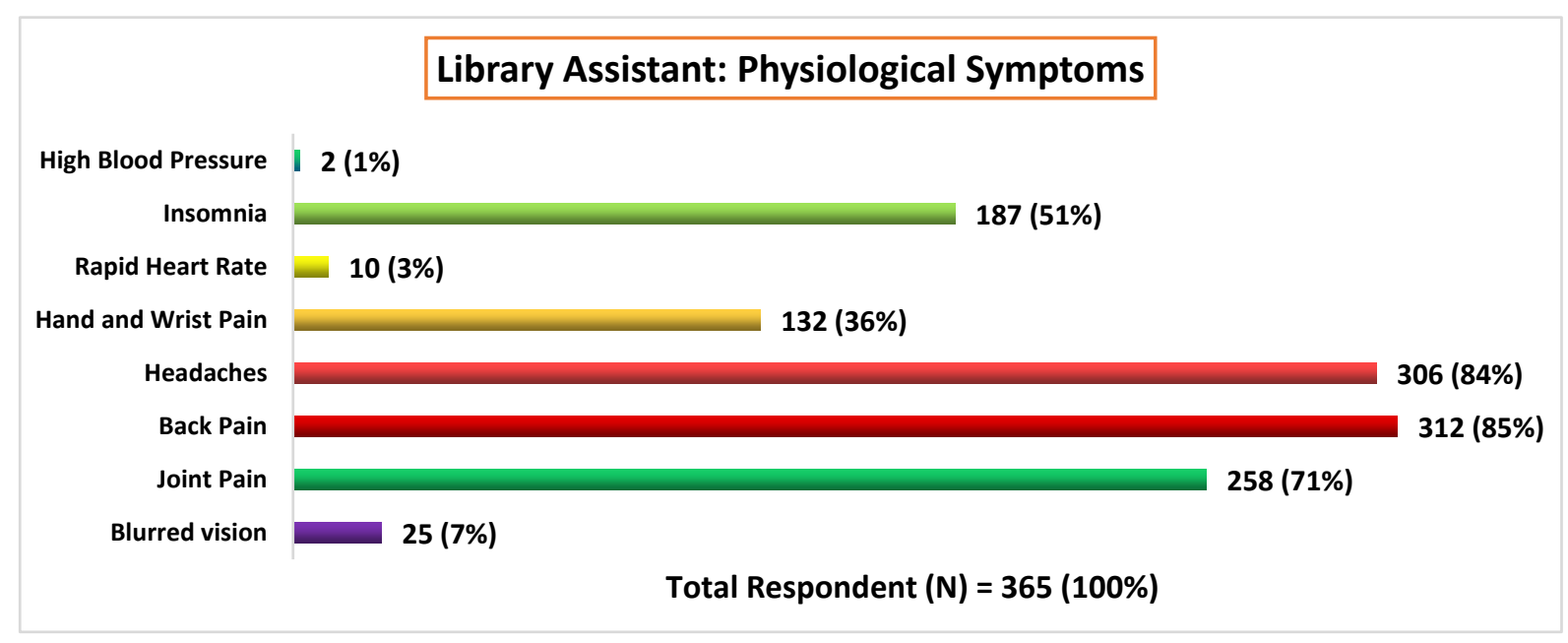

Fig. 12: Physiological Symptoms due to Technostress (Library Assistants)

Fig. 12 shows that out of the eight physiological symptoms, back pain (312 or $85 \%$ ), headaches (306 or $84 \%$ ), and joint pain ( 258 or $71 \%$ ) were chosen by a majority of the library assistants; whereas high blood pressure ( 2 or $1 \%)$ and rapid heart rate (10 or 3\%) were the least chosen.
Out of the 100 assistant librarians, a majority chose back pain (92 or $92 \%$ ), headaches ( 89 or $89 \%$ ), and joint pain ( 85 or $85 \%$ ), while high blood pressure $(0$ or $0 \%$ ) and rapid heart rate (5 or 5\%) were the least chosen (see Fig. $13)$. 


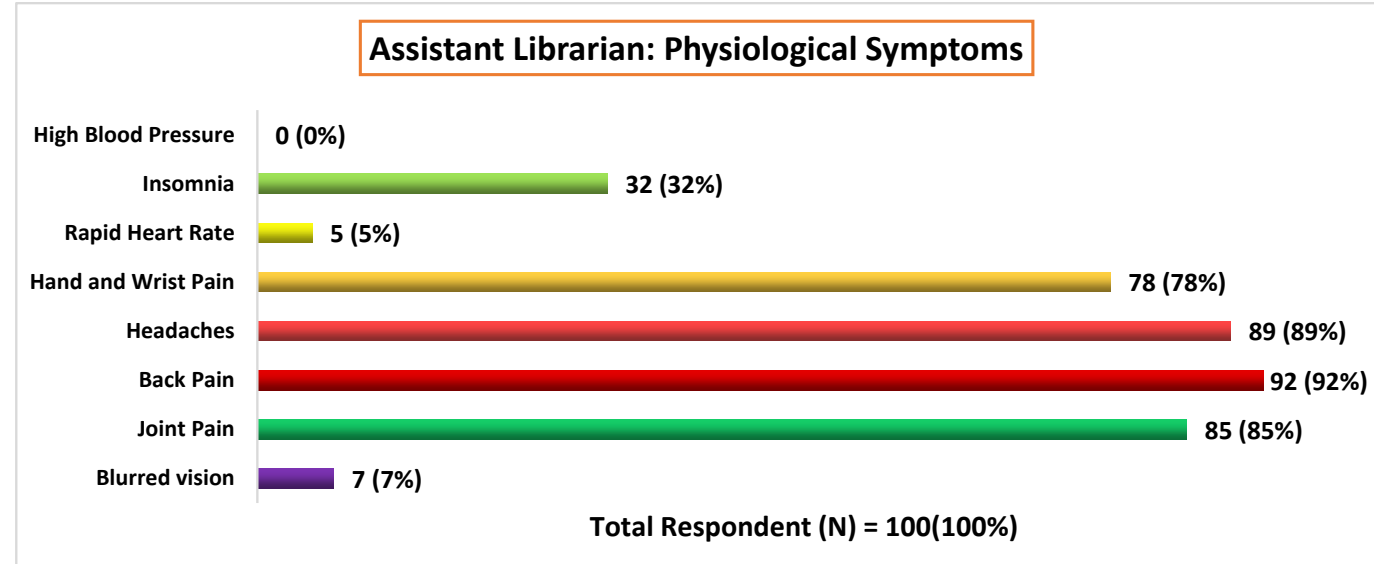

Fig. 13: Physiological Symptoms due to Technostress (Assistant Librarians)

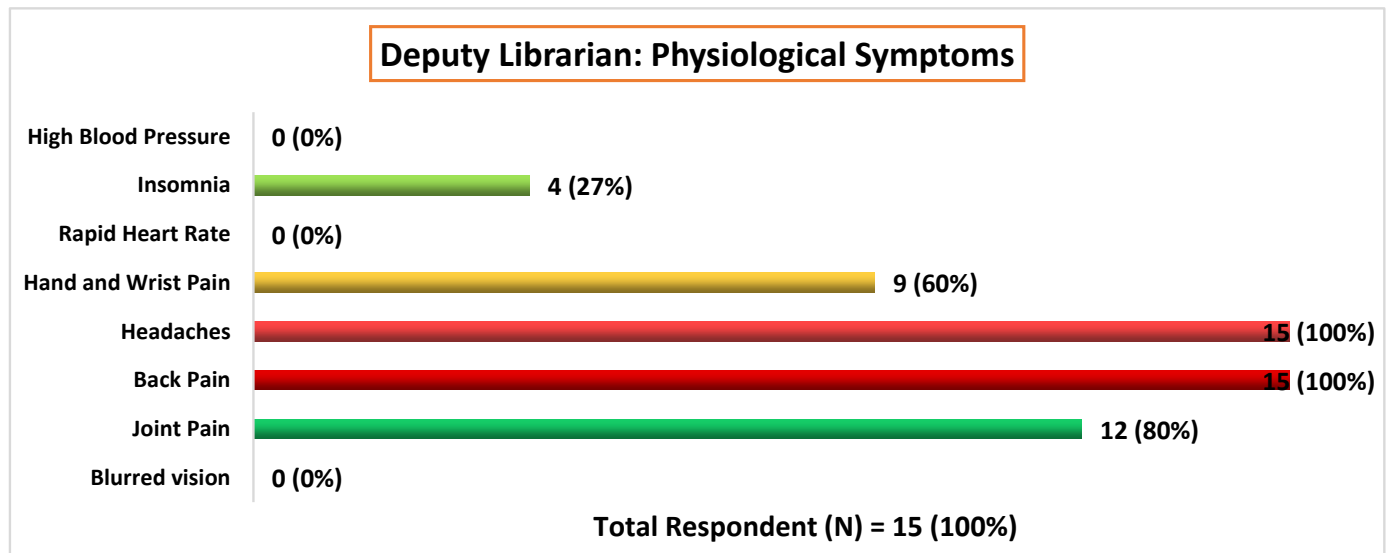

Fig. 14: Physiological Symptoms due to Technostress (Deputy Librarians)

According to Fig. 14, among the 15 deputy librarians, the top selected physiological symptoms were headaches (15 or $100 \%$ ), back pain (15 or $100 \%$ ), and joint pain
(12 or $80 \%$ ). The respondents did not choose symptoms like high blood pressure, rapid heart rate, and blurred vision.

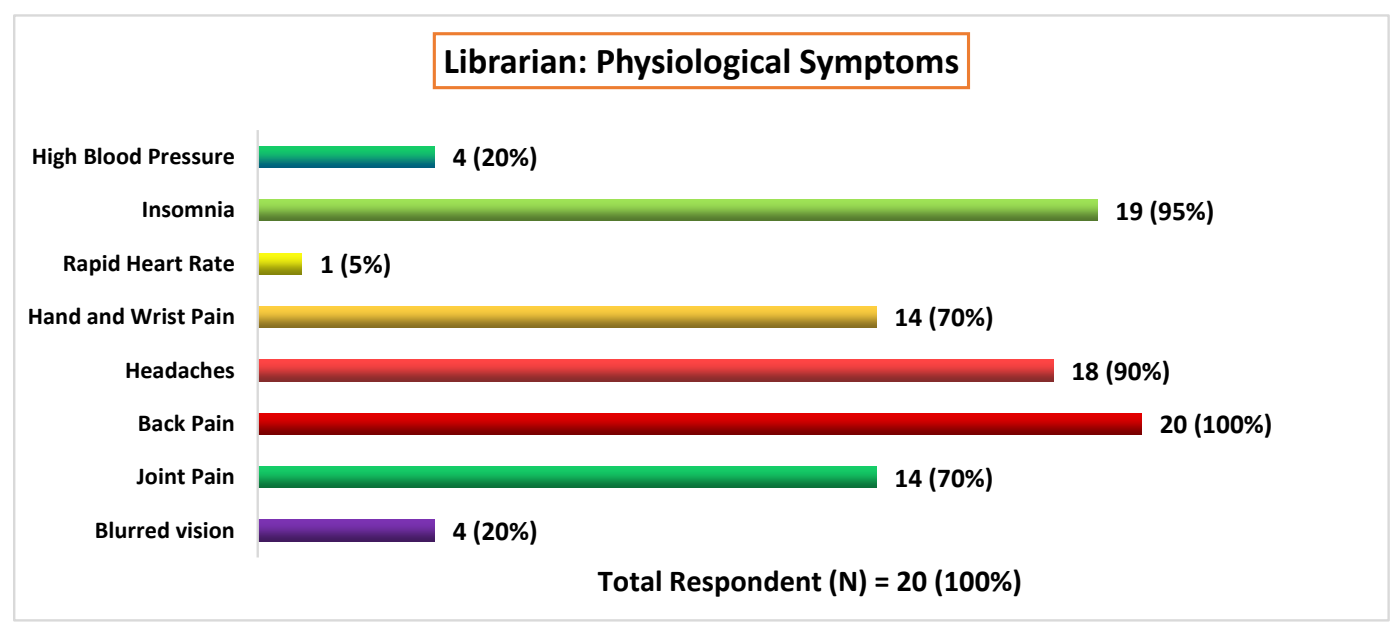

Fig. 15: Physiological Symptoms due to Technostress (Librarians or University Librarians) 
In the case of librarians or university librarians, out of the 20 respondents, back pain (20 or $100 \%$ ), insomnia (19 or $95 \%$ ), and headaches (18 or $90 \%$ ) were chosen by the majority; while rapid heart rate (1 or $5 \%$ ), high blood pressure (4 or $20 \%$ ), and blurred vision ( 4 or $20 \%$ ) were chosen the least chosen (see Fig. 15).

\section{Psychological Symptoms}

Out of several psychological symptoms, in this study, the following eight particular symptoms were selected for inclusion in the questionnaire.
- Computer anxiety

- Unrelenting stress

- Frustration

- Irritation (and anger)

- Scepticism

- Nightmares

- Mental fatigue

- Depression

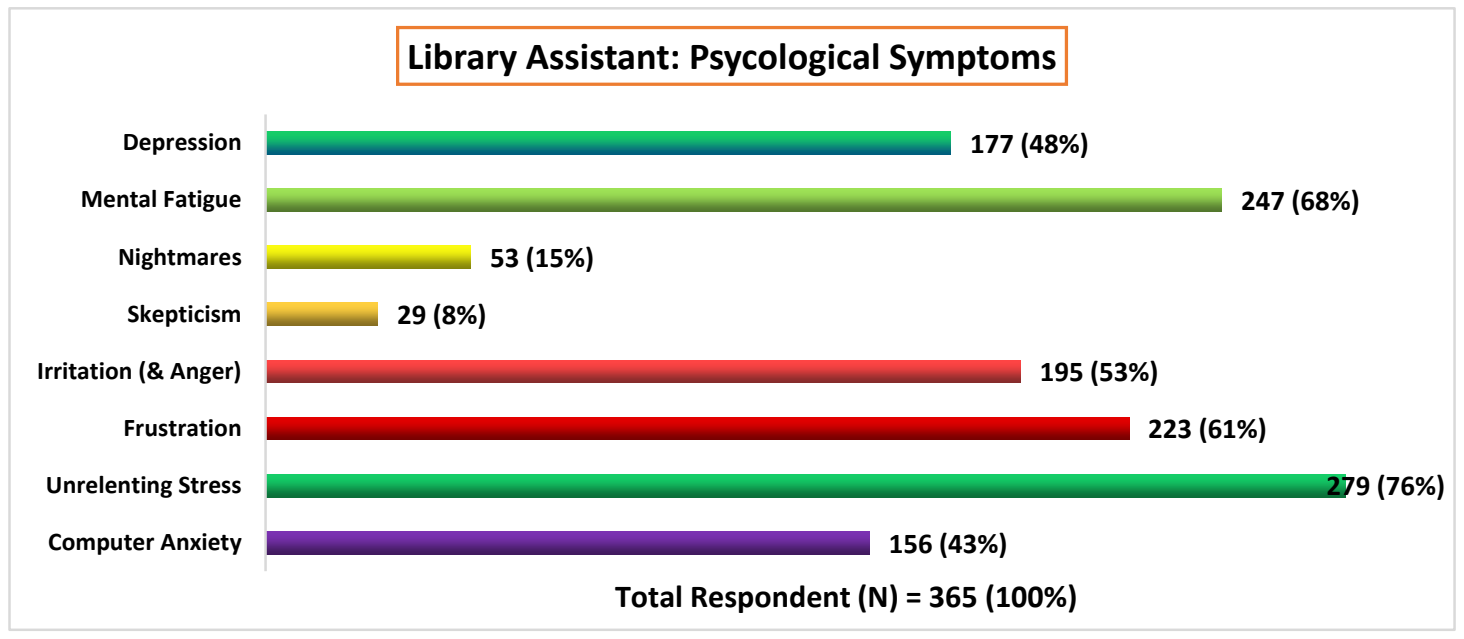

Fig. 16: Psychological Symptoms due to Technostress (Library Assistants)

From Fig. 16, it can be seen that library assistants chose unrelenting stress (279 or $76 \%$ ), mental fatigue (247 or $68 \%$ ), and frustration (223 or $61 \%$ ) as the top three psychological symptoms they suffer due to technostress, whereas scepticism (29 or $8 \%$ ) and nightmares (53 or $15 \%)$ were the least chosen ones.

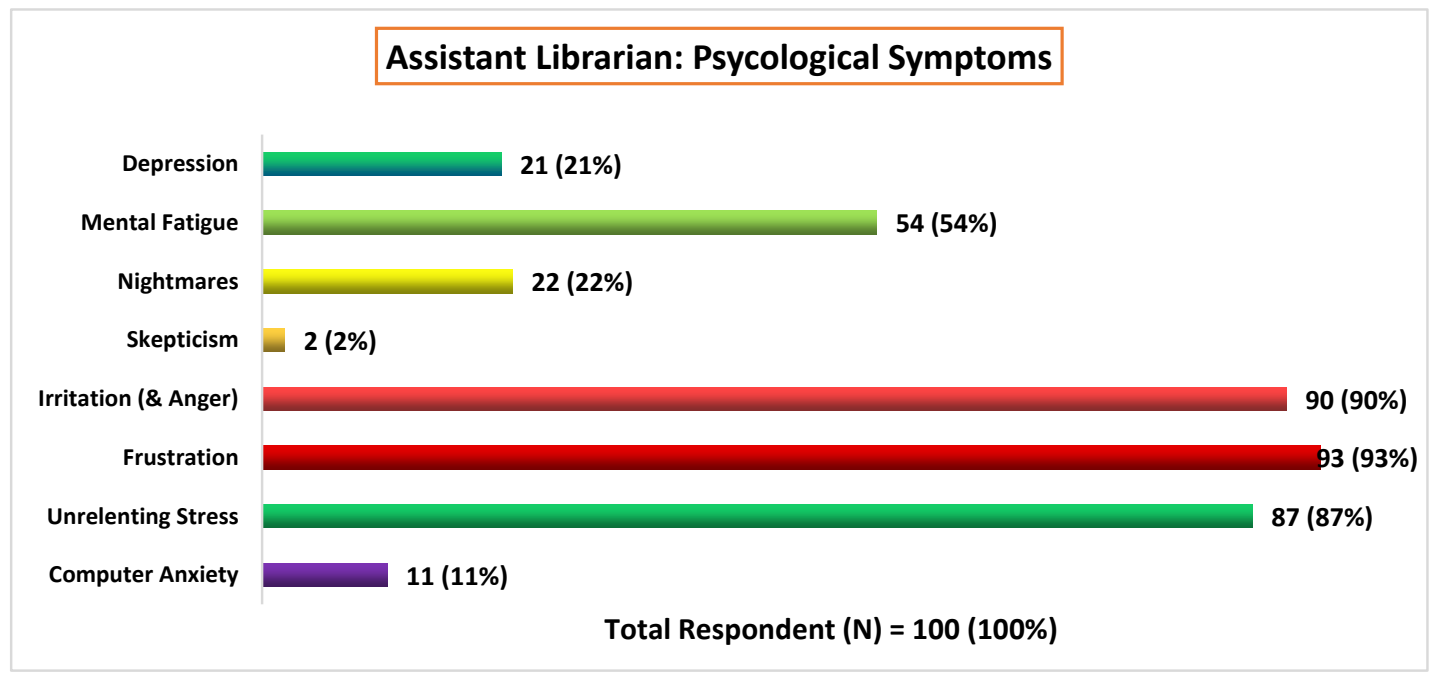

Fig. 17: Psychological Symptoms due to Technostress (Assistant Librarians) 
Fig. 17 shows that out of the eight psychological symptoms, frustration ( 93 or $93 \%$ ), irritation (and anger) (90 or $90 \%$ ), and unrelenting stress $(87$ or $87 \%$ ) were chosen by a majority of the assistant librarians, whereas scepticism ( 2 or $2 \%)$ and computer anxiety (11 or $11 \%)$ were the least chosen.

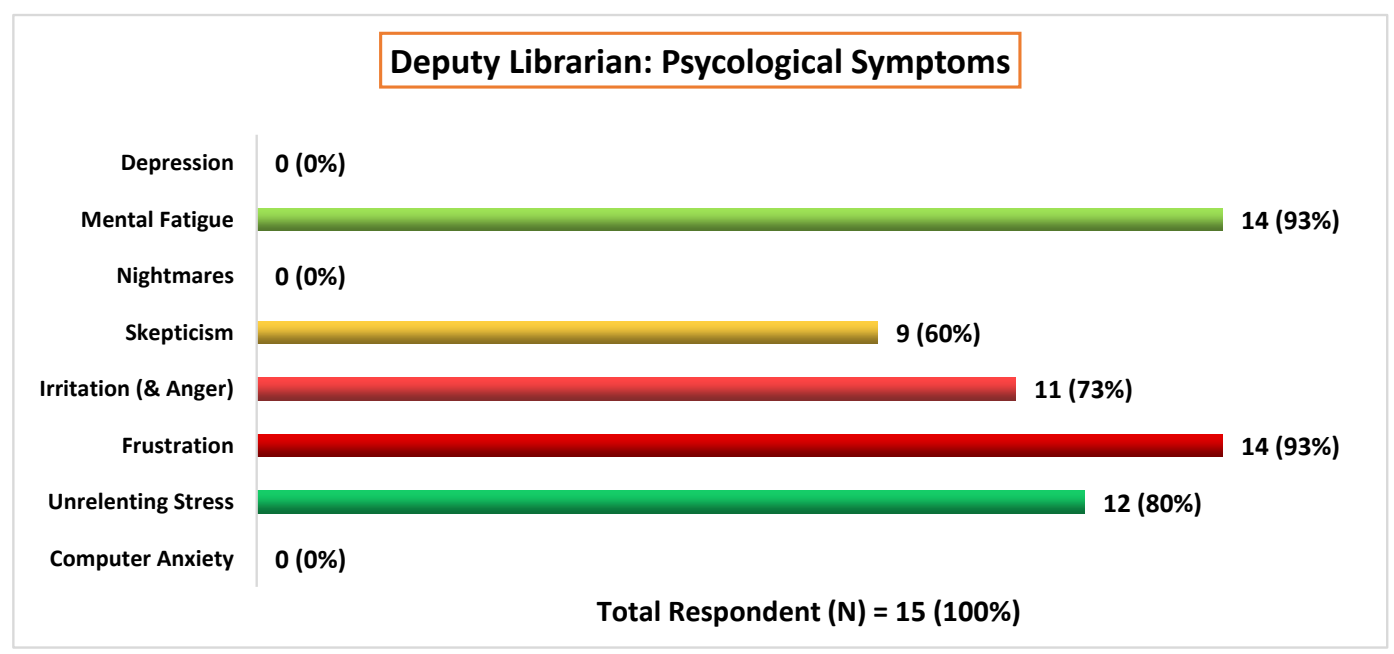

Fig. 18: Psychological Symptoms due to Technostress (Deputy Librarians)

In the case of deputy librarians, out of the 15 respondents, mental fatigue (14 or $93 \%$ ), frustration (14 or $93 \%$ ), and unrelenting stress (12 or $80 \%$ ) were chosen by a majority, while depression, nightmares, and computer anxiety were chosen by none as a psychological symptom they suffer due to technostress (see Fig. 18).

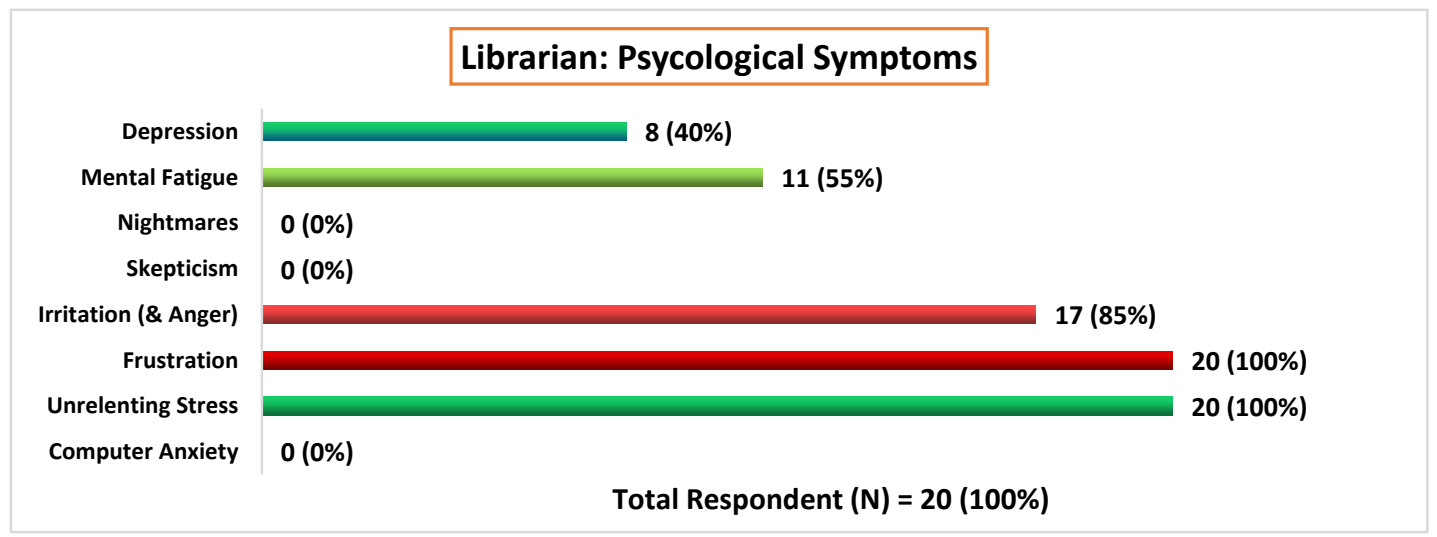

Fig. 19: Psychological Symptoms due to Technostress (Librarians or University Librarians)

According to Fig. 19, among the 20 librarians or university librarians, the top selected psychological symptoms were frustration (20 or $100 \%$ ), unrelenting stress (20 or $100 \%$ ), and irritation (and anger) (17 or $85 \%$ ). The respondents did not choose symptoms like nightmares, scepticism, and computer anxiety.

\section{Selection of Possible Coping Strategies}

The phenomenon of technostress not only makes major demands on identifying the root causes and major symptoms (physiological and/or psychological) of LIS professionals, but also requires a good understanding of how LIS professionals can cope with varying demands set by IT (Pirkkalainen et al., 2017). In the beginning, Lazarus (1966) stated, "coping is part of the stress process, in that it is a response to the stress-creating conditions that individuals experience". Again, in 1984, Lazarus and Folkman defined coping "as individuals' psychological and behavioural efforts to deal with events that are appraised as demanding or exceeding the resources possessed by the individual". The following are ten such coping strategies 
included in the research questionnaire as a multi-response question for the online survey used in this study.

- Technology-based education and training for both library staff and users

- Developing a positive attitude towards technology

- Providing adequate equipment and technical support

- Regular breaks while using technology
- Avoiding multitasking

- Effective time management

- Regular physical exercise and meditation

- Stress inoculation training

- Work recognition by way of rewards publicly

- Better ergonomics practice

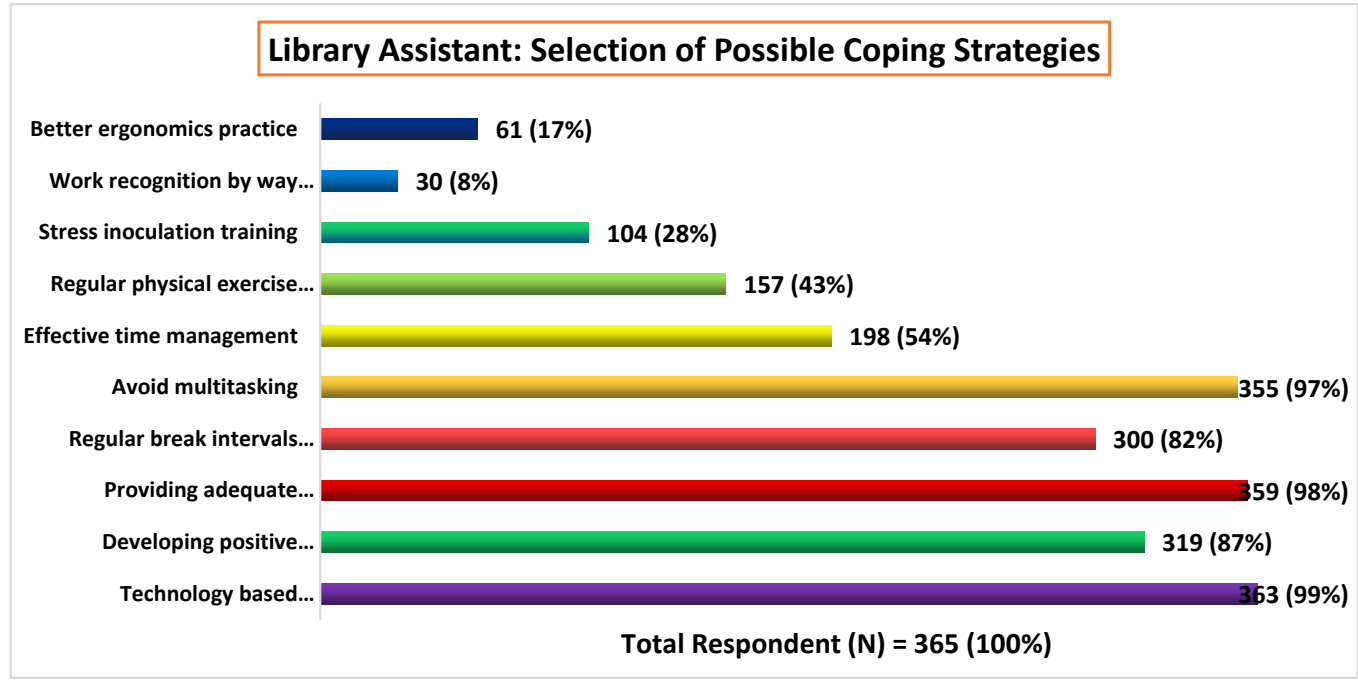

Fig. 20: Selection of Possible Coping Strategies (Library Assistants)

Among the 365 library assistants, the top selected coping strategies for technostress were technology-based education and training for both library staff and users (363 or $99 \%$ ), providing adequate equipment and technical support (359 or $98 \%$ ), and avoiding multitasking (355 or $97 \%$ ), whereas work recognition by way of rewards publicly (30 or $8 \%$ ) and better ergonomics practice (61 or $17 \%$ ) were the least chosen.

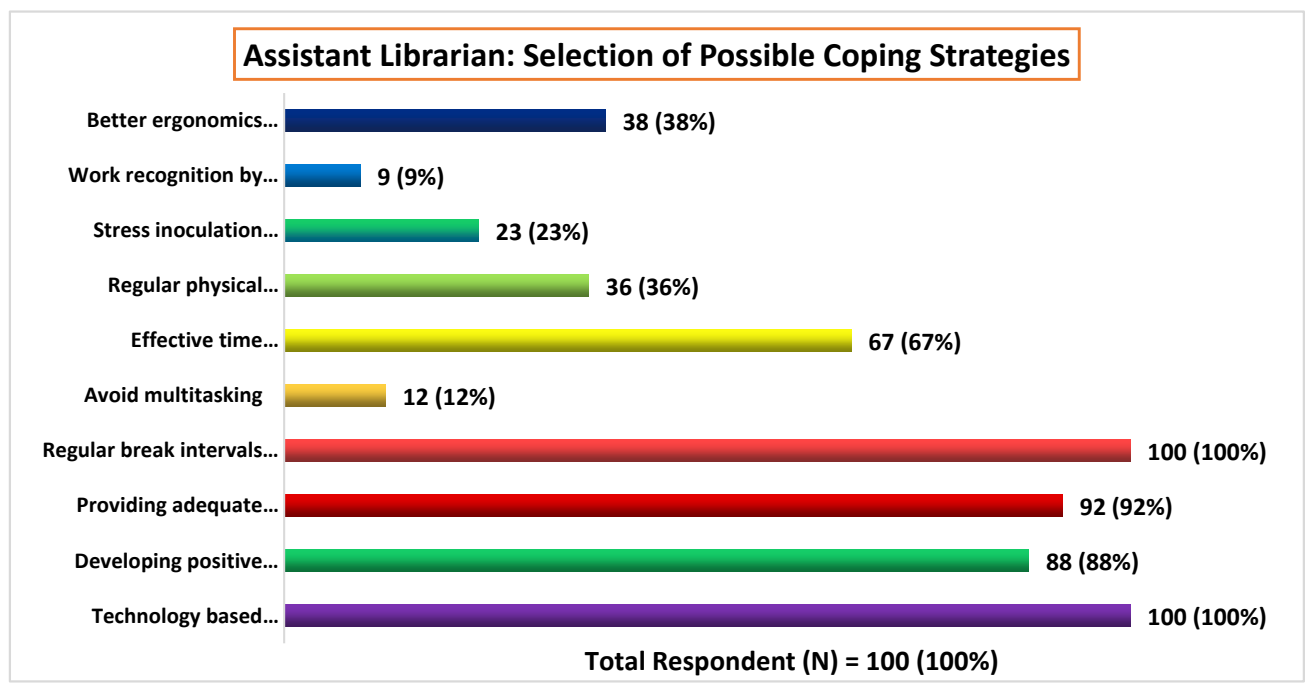

Fig. 21: Selection of Possible Coping Strategies (Assistant Librarians) 
14 International Journal of Information Studies \& Libraries

In the case of assistant librarians, all the 100 $(100 \%)$ respondents chose regular breaks while using technology and technology-based education and training for both library staff and users as successful coping

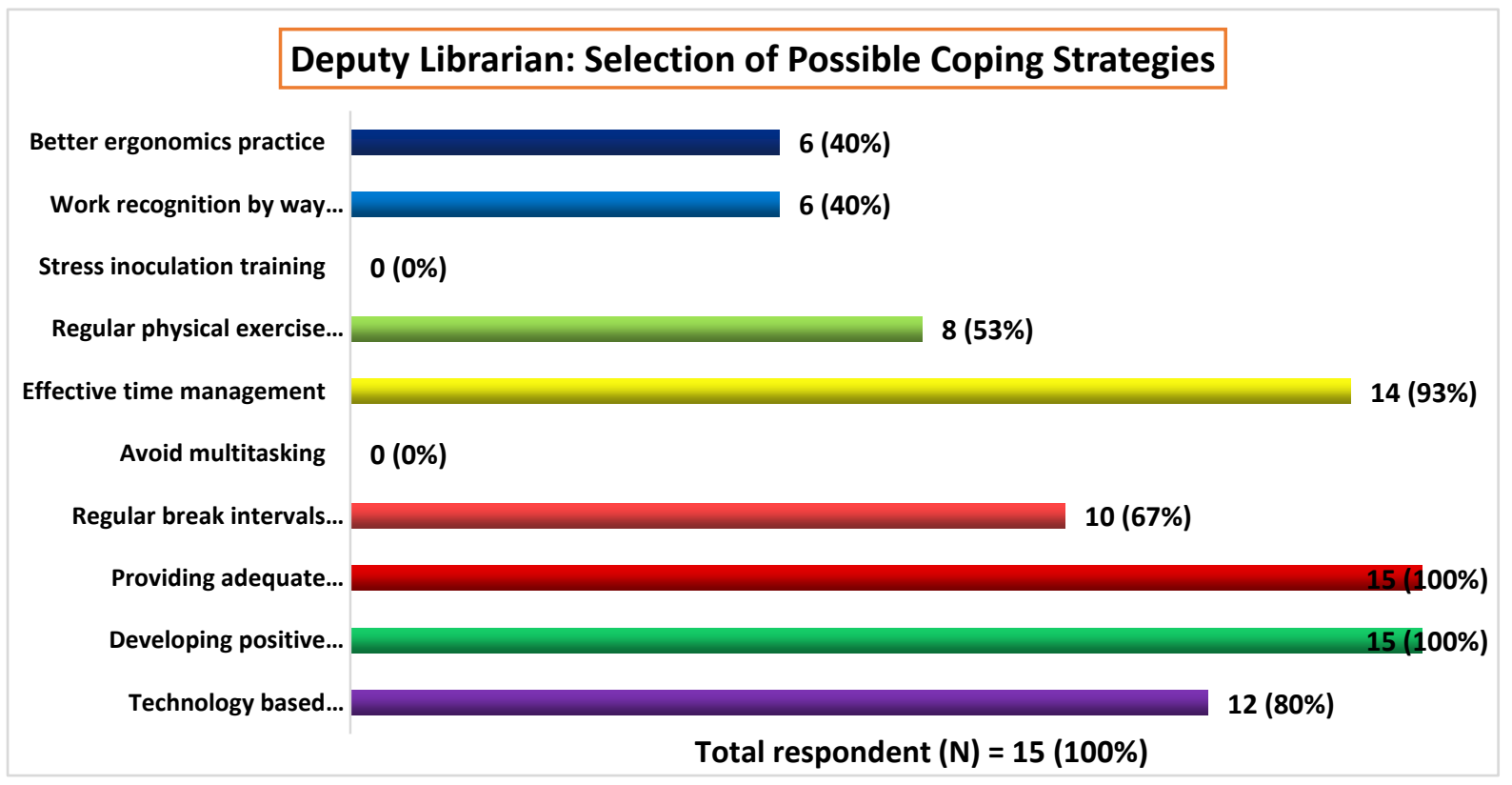

Fig. 22: Selection of Possible Coping Strategies (Deputy Librarians)

Out of the 15 deputy librarians, a majority of the respondents chose providing adequate equipment and technical support (15 or $100 \%$ ), developing a positive attitude towards technology (15 or $100 \%$ ), and effective strategies for their technostress, while work recognition by way of rewards publicly ( 9 or $9 \%$ ) and avoiding multitasking ( 12 or $12 \%$ ) were the least chosen strategies (see Fig. 21).

(

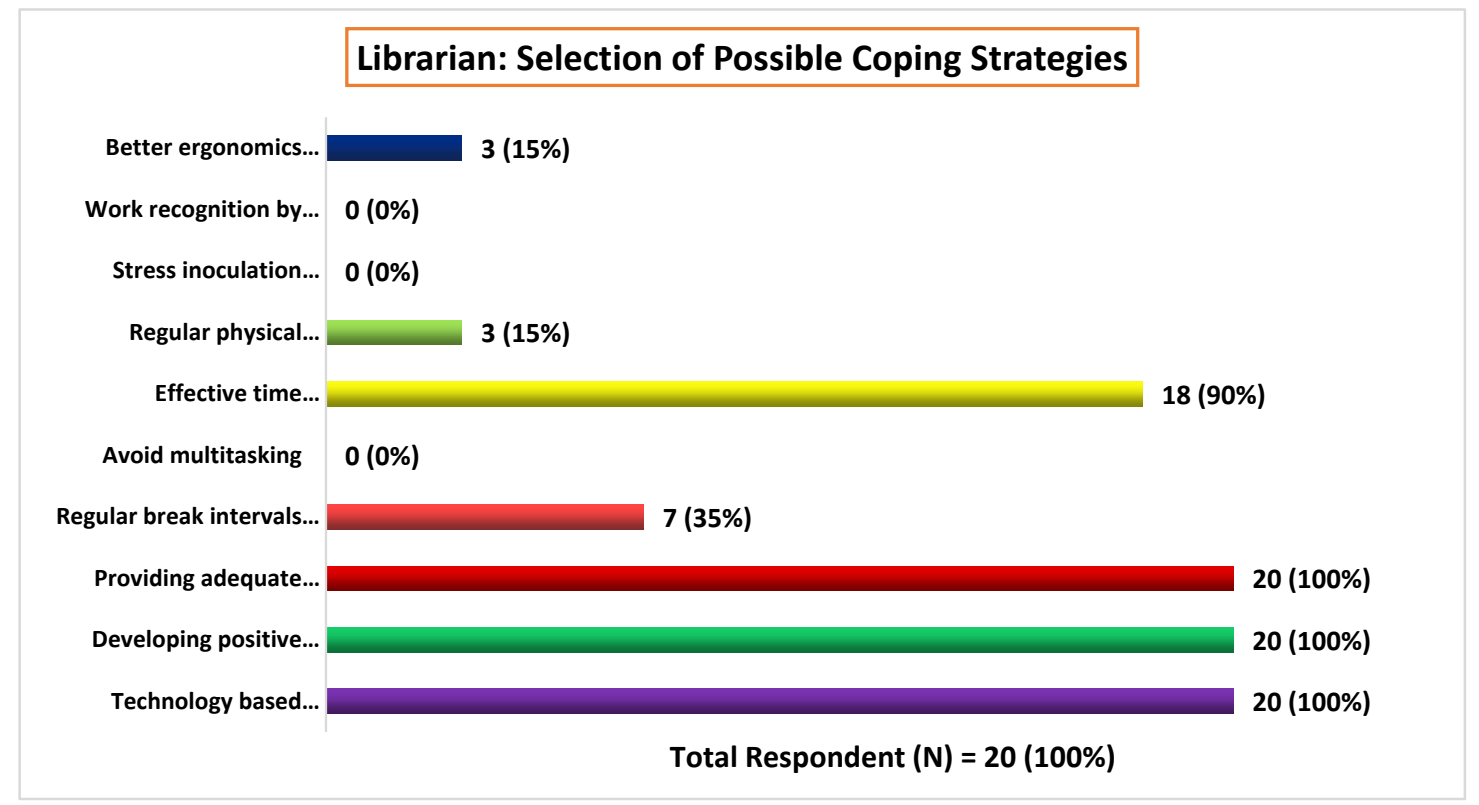

Fig. 23: Selection of Possible Coping Strategies (Librarians or University Librarians) 
Fig. 23 shows that $100 \%$ (20) of the librarians or university librarians chose providing adequate equipment and technical support, developing a positive attitude towards technology, and technology-based education and training for both library staff and users for successfully coping with technostress; alternatively, work recognition by way of rewards publicly, stress inoculation training, and avoiding multitasking were chosen by none.

\section{Summary of Findings}

This paper is the study of identifying and prioritising the causes, physiological and psychological symptoms, and coping strategies among library professionals through an online survey. The following are some major findings from the study:

- Among the library professionals, a majority (341 or $68 \%$ ) have four to eight hours of techno-working time, whereas, $18 \%$ (or 89 ) have $>8$ hours and $14 \%$ (or 70) have zero to four hours (see Fig. 5).

- A majority of the library professionals (382 or $76 \%$ ) were identified as suffering from moderately perceived technostress, while 14\% (or 70) suffered low levels, and 10\% (or 48) suffered high levels (see Fig. 6).

- From Fig. 7 it can be identified that there is a positive relation between techno-working hours and the perceived stress levels of library professionals.

- Among the causes of technostress:

- Increased workload (99\% or 362) was a factor chosen by a majority of the library assistants.

- Prolonged sitting in front of the computers (100 or $100 \%$ ) was chosen by all the assistant librarians.

- Prolonged sitting in front of the computers and information overload were chosen by all (15 or $100 \%$ ) of deputy librarians.

- Networking problems and security issues were chosen by all (20 or $100 \%$ ) the librarians or university librarians (see Fig. 8-11).

- Among the physiological symptoms:

- A majority (312 or $85 \%$ ) of the library assistants suffer from back pain.

- A majority (92 or $92 \%$ ) of the assistant librarians suffer from back pain.
- All (15 or $100 \%)$ the deputy librarians suffer from headaches and back pain.

- All (20 or $100 \%)$ the librarians or university librarians suffer from back pain (see Fig. 12-15).

- Among the psychological symptoms:

- A majority ( 279 or $76 \%$ ) of the library assistants suffer from unrelenting stress.

- A majority (93 or 93\%) of the assistant librarians suffer from frustration.

- A majority (14 or $93 \%$ ) of the deputy librarians suffer from mental fatigue and frustration.

- All (20 or $100 \%)$ the librarians or university librarians suffer from frustration and unrelenting stress (see Fig. 16-19).

- Among the effective coping strategies against technostress:

- Technology-based education and training for both library staff and users was chosen by a majority (99\% or 363 ) of the library assistants.

- Regular break intervals while using technology and technology-based education and training for both library staff and users were chosen by all (100 or $100 \%)$ the assistant librarians.

- Providing adequate equipment and technical support and developing a positive attitude towards technology were chosen by all (15 or $100 \%)$ the deputy librarians.

- Providing adequate equipment and technical support, developing a positive attitude towards technology, and technology-based education and training for both library staff and users were chosen by all (20 or $100 \%$ ) the librarians or university librarians (see Fig. 20-23).

\section{Positive Technology for Technostress Prevention and Management: A Proposal}

As technology and use of IT is essential in libraries, adopting a positive technology perspective in designing not just the technologies, but also the work processes is very important. This is the first step in preventing technostress and its related techno-stressors, and having 
happy, healthy, and satisfied staff, and an efficient and productive organisation (Brivio et al., 2018). There have been several attempts made by organisations to counteract techno-stressors (Dello lacovo, 2012; Tarquini, 2014). A scientific approach that has proven to be highly effective in producing a positive change is positive psychology (Seligman \& Csikszentmihalyi, 2000; Seligman, 2002), and its derivative, positive technology (Calvo \& Peters, 2012; Riva et al., 2012, 2014). Positive psychology postulates that personal experiences can be leveraged to foster well-being and personal growth. Similarly, positive technology is "the scientific and applied approach to the use of technology for improving the quality of our personal experience" (Riva et al., 2012).

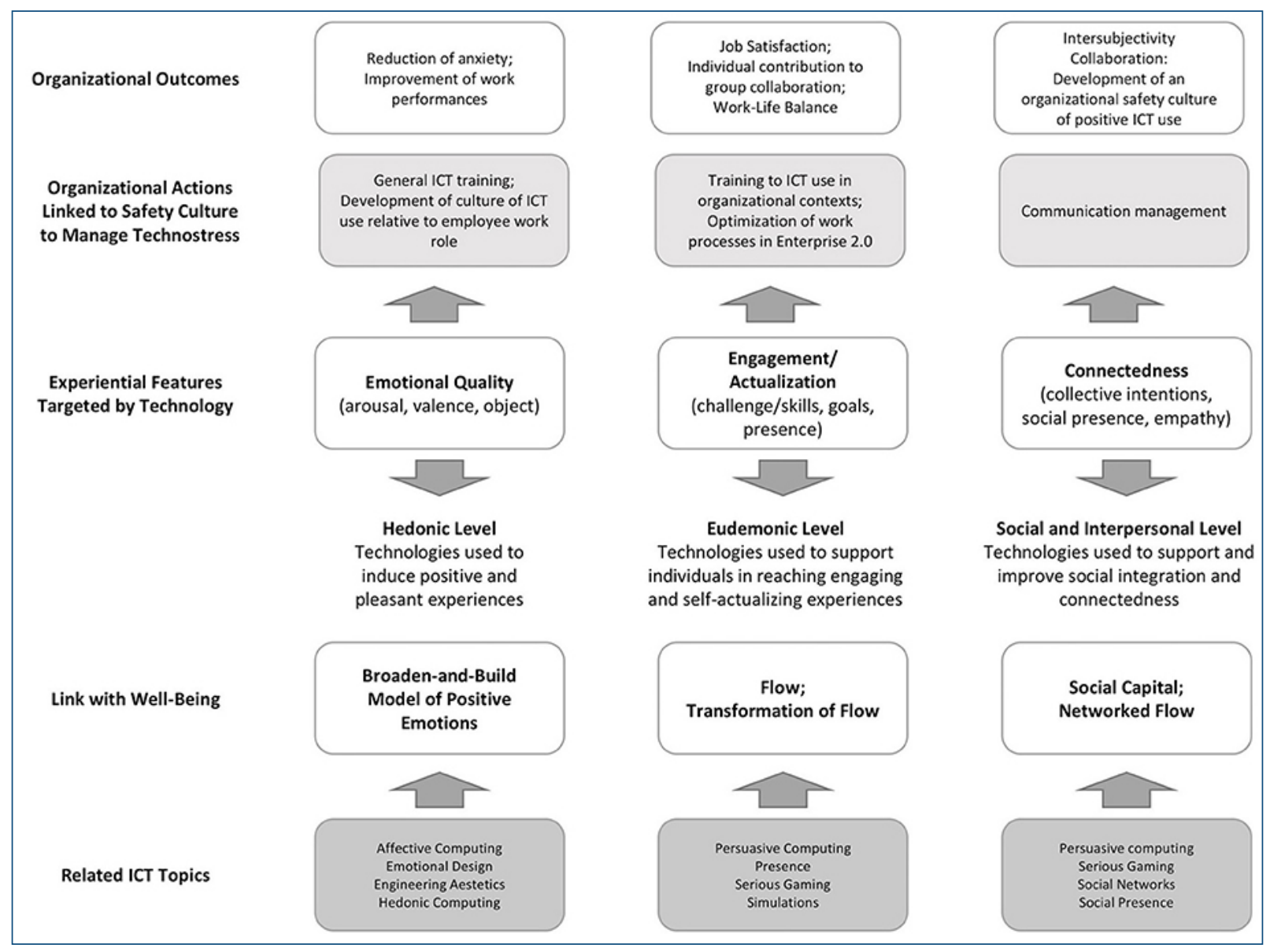

Fig. 24: Positive Technology Domains and their Application to Organisational Safety Culture (Adapted from Riva et al., 2012)

As modelled by Riva et al. (2012), positive technology domains are shown in the lower part of Fig. 24, while the corresponding indicators of organisational culture protection is shown at the top. The combined output of these actions will create positive experiences while working with IT, and reduce technostress at the organisational level. It should be noted that the work culture of the organisation mediates between the result of the organisation and the use of technology. The following are the three areas of personal experience influenced by positive technology:
- Hedonic: At the individual level, positive emotions can be induced if the technologies are well designed and compatible with the role of a particular staff within the library.

- Eudaimonic: A technology within a work setting can generate an effect at this level if it is designed correctly, and staff training is performed accordingly.

- Social/Interpersonal: Many libraries are moving towards systems that exploit collaborative intelligence processes, requiring the staff to communicate with each other to generate a competitive advantage. 
All the three areas can be used as a suggestive measure to identify the root cause of technostress, and it may be applied both in a preventive and a corrective way. Previous literature shows that the positive technology approach rarely has been applied preventively; however, the preventive perspective may prove to have more impact and have lasting effects, both on employees and organisations, as it can be easily included in an organisation's safety culture (Brivio et al., 2018). This is, however, only a theoretical framework as this approach is neither $100 \%$ accurate nor without limitations. It is not possible for all organisations to structure their IT infrastructure to stimulate the hedonic, eudaimonic, and social/interpersonal levels of personal experience separately. Again, the working efficiency of this model can only be judged after its successful implementation and through observation.

\section{Conclusion}

Thus, it is evident that in the $21 \mathrm{st}$ century, ICT has undoubtedly revolutionised modern-day life, while at the same time bringing with it new problems. Today, the application of technology has become a trend in libraries as it is generally found to enhance the efficiency and effectiveness of library services. Nevertheless, it is essential to realise the negative impacts of technology. It has become very critical in recent times for library professionals to keep abreast of the latest technology, to continue to be relevant in their profession. Library professionals need to adjust themselves to the changing library environment and new formats of technologies, develop new technical skills, and learn to handle different metadata available in the library. Libraries should select both hardware and software applications that fit their working environment. This is essential because the library environment will keep changing to keep pace with technological developments. Hence it is necessary to create awareness about technostress and its effects, and possible ways to manage it. The positive technology approach for technostress gives a theoretical framework and three possible suggestions for the prevention and management of technostress at the organisational level. Ultimately, it can be concluded that the easier the library professional's interaction with technology, the lesser the technostress.

\section{References}

Aghwotu, P. T., \& Owajeme, O. J. (2010). Technostress: Causes, symptoms and coping strategies among librarians in university libraries. Educational Research, 1(12), 713-720.

Ahmad, U. N. U., \& Amin, S. M. (2012). The dimensions of technostress among academic librarians. Procedia - Social and Behavioral Sciences, 65, 266-271. doi: https://doi.org/10.1016/j.sbspro.2012.11.121

Al-Qallaf, C. L. (2006). Librarians and technology in academic and research libraries in Kuwait: Perceptions and effects. Libri, 56(3). doi:https://doi.org/10.1515/ libr.2006.168

Arnetz, B. B., \& Wiholm, C. (1997). Technological stress: Psychophysiological symptoms in modern offices. Journal of Psychosomatic Research, 43(1), 35-42. doi: https://doi.org/10.1016/s0022-3999(97)00083-4

Brillhart, P. E. (2004). Technostress in the workplace: Managing stress in the electronic workplace. Journal of American Academy of Business, Cambridge, 5, 302-307.

Brivio, E., Gaudioso, F., Vergine, I., Mirizzi, C. R., Reina, C., Stellari, A., \& Galimberti, C. (2018). Preventing technostress through positive technology. Frontiers in Psychology, 9. doi:https://doi.org/10.3389/ fpsyg.2018.02569

Brod, C. (1984). Technostress: the human cost of the computer revolution. Addison-Wesley, Reading.

Calvo, R. A., \& Peters, D. (2012). Positive computing. Interactions, 19(4), 28-31. doi:https://doi. org/10.1145/2212877.2212886

Dello Iacovo, L. (2012, March 31). Always connected? Volkswagen is not the only one that blocks emails to employees after $7 \mathrm{pm}$. The other cases. IlSole24ore. Retrieved from shorturl.at/bjDM6

Gaudioso, F., Turel, O., \& Galimberti, C. (2017). The mediating roles of strain facets and coping strategies in translating techno-stressors into adverse job outcomes. Computers in Human Behavior, 69, 189-196. doi:https://doi.org/10.1016/j.chb.2016.12.041.

Hsiao, K. L. (2017). Compulsive mobile application usage and technostress: The role of personality traits. Online Information Review, 41(2), 272-295. doi: https://doi.org/10.1108/oir-03-2016-0091.

Jena, R. K., \& Mahanti, P. K. (2014). An empirical study of Technostress among Indian academicians. International Journal of Education and 
Learning, 3(2), 1-10. doi:https://doi.org/10.14257/ ijel.2014.3.2.01

Khasawneh, O. (2018, March). The conceptual gap between technophobia and computer anxiety and its empirical consequences. Global Information Technology Management (GITMA) World Conference.

Lazarus, R. S. (1966). Psychological stress and the coping process. McGraw-Hill, New York.

Lazarus, Richard S, \& Folkman, S. (1984). Stress, appraisal, and coping. Springer, New York.

Mark, G., Gudith, D., \& Klocke, U. (2008). The cost of interrupted work: More speed and stress. Proceedings of ACM CHI 2008 Conference on Human Factors in Computing Systems, April 5-10, 2008, pp. 107-110. doi:https://doi.acm.org/10.1145/1357054.1357072

Ogada, H., Kwanya, T., \& Kiplang'at, J. (2019). Technostress among technical university librarians in Kenya. In Digital Technologies for Information and Knowledge Management. The Technical University of Kenya. Retrieved from shorturl.at/hiqzN

Owolabi, S., Aregbesola, A., \& Oyesola, O. (2015). Technostress, Library Staff and Productivity: Ray on Landmark University Library. Journal of Applied Information Science and Technology, 8(1), 9-15. Retrieved from https://www.jaistonline.org/ vol8no1 2k15.html

Pirkkalainen, H., Salo, M., Makkonen, M., \& Tarafdar, M. (2017). Coping with technostress: When emotional responses fail. Thirty Eighth International Conference on Information Systems, 1-17. Retrieved from https:/www.researchgate.net/ publication/332834923

Ragu-Nathan, T. S., Tarafdar, M., Ragu-Nathan, B. S., \& Tu, Q. (2008). The consequences of technostress for end users in organizations: Conceptual development and empirical validation. Information Systems Research, 19(4), 417-433. doi:https://doi. org/10.1287/isre.1070.0165

Riva, G., Baños, R. M., Botella, C., Wiederhold, B. K., \& Gaggioli, A. (2012). Positive technology: Using interactive technologies to promote positive functioning. Cyberpsychology, Behavior, and Social Networking, 15(2), 69-77. doi:https://doi. org/10.1089/cyber.2011.0139

Riva, G., Gaggioli, A., Villani, D., Cipresso, P., Repetto, C., Serino, S., Triberti, S., Brivio, E., Galimberti, C., \& Graffigna, G. (2014). Positive technology for healthy living and active ageing. In G. Riva, P. A. Marsan, \& C. Grassi (Eds.), Active Ageing and Healthy Living (pp. 44-56). IOS Press. Retrieved from http://ebooks.iospress.nl/publication/37278

Sami, L. K., \& Pangannaiah, N. B. (2006). Technostress a literature survey on the effect of information technology on library users. Library Review, 55(7), 429-439. doi:https://doi.org/10.1108/00242530610682146

Seligman, M. E. P. (2002). Authentic happiness: Using the new positive psychology to realize your potential for lasting fulfilment. Atria Paperback, New York.

Seligman, M. E. P., \& Csikszentmihalyi, M. (2000). Positive psychology: An introduction. American Psychologist, 55(1), 5-14. doi:https://doi. org/10.1037/0003-066x.55.1.5

Tarafdar, M., Ragu-Nathan, B., Ragu-Nathan, T. and Tu, Q. (2005). Exploring the impact of technostress on productivity. In Proceedings of the $36^{\text {th }}$ Annual Meeting of the Decision Sciences Institute. San Francisco.

Tarquini, A. (2014, February 16). BMW revolutionizes working hours: Even emails and SMS are counted. La Repubblica. Retrieved from shorturl.at/yHK68

Wang, K., Shu, Q., \& Tu, Q. (2008). Technostress under different organizational environments: An empirical investigation. Computers in Human Behavior, 24(6), 3002-3013. doi:https://doi.org/10.1016/j. chb.2008.05.007

Weil, M. M., \& Rosen, L. D. (1997). TechnoStress: Copingwith technology@work@home@play.J. Wiley.

Yuvaraj, M., \& Singh,A. K. (2015). Effects and measures of technostress among librarians in selected University Libraries of Delhi. Library Philosophy and Practice (e-Journal), Summer (1293). Retrieved from https:// digitalcommons.unl.edu/libphilprac/1293/

\section{Further Reading}

Clark, K., \& Kalin, S. (1996). Technostressed out? How to cope in the digital age. Library Journal, 121(13), 3032. Retrieved from https://eric.ed.gov/?id=EJ529677

Davis-Millis, N. (1998). Technostress and the organization - A manager's guide to survival in the information age. Retrieved from https://web.mit.edu/ninadm/www/mla.htm

DeLoughry, T. (1993). 2 researchers say "Technophobia" may affect millions of students. Chronicle of 
Higher Education. Retrieved from https://eric. ed.gov/?id=EJ462778

Owusu-Ansah, S., Azasoo, J. Q., \& Adu, I. N. (2016). Understanding the effects of techno-stress on the performance of banking staff. International Journal of Business Continuity and Risk Management, 6(3),
222-236. Retrieved from https://doi.org/10.1504/ IJBCRM.2016.079010

Quinn, B. (2000). Overcoming technostress in reference services to adult learners. The Reference Librarian, 33(69-70), 49-62. doi:https://doi.org/10.1300/ J120v33n69_05 